\title{
Development of a Multiple SMPS System for High Power LED
}

\author{
Junho Ko and Yoon Sang Kim \\ School of Computer Science and Engineering, Korea University of Technology \\ and Education (KOREATECH), Cheonan, Republic of Korea \\ lich126@koreatech.ac.kr,yoonsang@koreatech.ac.kr
}

\begin{abstract}
As a high-power LED (light emitting diode) technology has diversified recently, the demand for a high-power SMPS (switched-mode power supply) to activate the devices is also growing. This paper presents a multiple SMPS system for the high-power LED. The proposed system provides power up to $1.2 \mathrm{~kW}$ by extending our previous multiple SMPS system [1, 2], which was designed for controlling variable-load-based output power and monitoring based on a wireless network. Two tests, a performance measurement test with an actual power load (LED) and the other test by KOLAS (Korea Laboratory Accreditation Scheme), the national certification institution, are conducted to examine the performance of the proposed system.
\end{abstract}

Keywords: SMPS, Power supply, Load control, Remote control, Wireless network

\section{Introduction}

The recent high specification trend among personal, industrial, and medical devices has shed light on the importance of high power supply devices. The increasing usage of high power devices has also created a growth in demand for AC-DC converters. The AC-DC converter is a SMPS which receives alternating current power source and outputs as a continuous current in consistent amounts to operate electrical devices using DC power supply.

Since power supply devices are indispensable to computer and electronic components, stability and reliability are critical factors. The recent increase of power consumption and load emphasizes power quality. Among the possible damages that can be caused by power quality degradation, some of the most frequent causes that undermine industrial productivity or damage sensitive devices include interruption, sag, and swell [3]. The system configuration embedded with root mean square calculation and analytic algorithm is required to solve such problems [4]. The damages caused by power quality degradation are also on the rise, which calls for further studies on the power quality monitoring and diagnostic system [5]. To overcome these limitations, the SMPS is developed to monitor the variation of the load in real time and to ensure that the power supply is safe and stable [2]. However, as the method of high-power LED has diversified recently [6-10], the demand for a high-power SMPS to activate the devices is also growing.

This paper presents a multiple SMPS system for the high-power LED. It uses the existing $200 \mathrm{~W}$ SMPS [1] as a unit module, allowing a power supply of up to $1.2 \mathrm{~kW}$. IN addition, the functions of the system include controlling the variable-load-based output power [2] and monitoring based on a wireless network. Two tests, a performance measurement test with an actual power load (LED) and the other test by KOLAS, the national certification institution, are conducted to examine the performance of the proposed system.

Received (July 10, 2017), Review Result (October 30, 2017), Accepted (November 11, 2017) 


\section{Multiple SMPS System for High Power LED}

The proposed system is composed of a multiple SMPS system and a remote control part as shown in Figure 1. The multiple SMPS part is composed of three single SMPSs (each single SMPS is a unit module of $200 \mathrm{~W}$ ): power factor correction (PFC), interface board, and Zigbee module. The remote control part has a role in controlling and monitoring the power supply part, and comprises the Zigbee module, a mobile device (Android-based tablet and smartphone), and a database (DB) server.

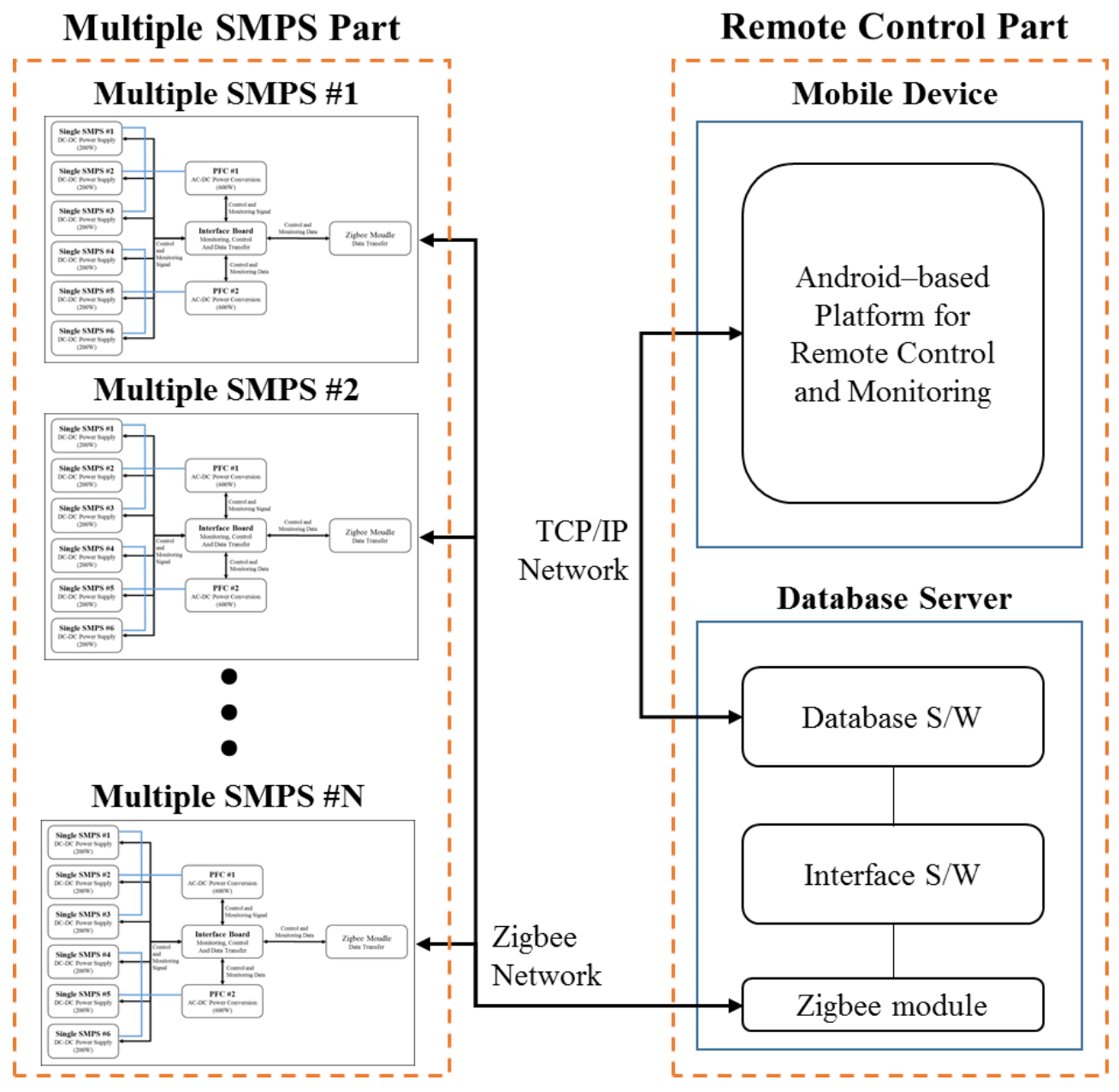

Figure 1. Structure of the Proposed Multiple SMPS System

\subsection{Multiple SMPS Part}

The proposed multiple SMPS part is designed to control the output power on the basis of a variable load, and comprises six single SMPSs [1], two PFCs, an interface board, and a Zigbee module as shown in Figure 2. The Zigbee module transmits SMPS monitoring data (voltage, current, and temperature) received from the interface board to the remote control part. The SMPS control data received from the remote control part are then transmitted to the interface board. The interface board controls the PFC and the six single SMPS modules according to the delivered control data. Further, the board passes on the monitoring data to the remote control part via the Zigbee module through the ADC of the monitoring signals. The PFC controls the three single SMPSs and supplies power by converting DC power to $\mathrm{AC}$ power. 


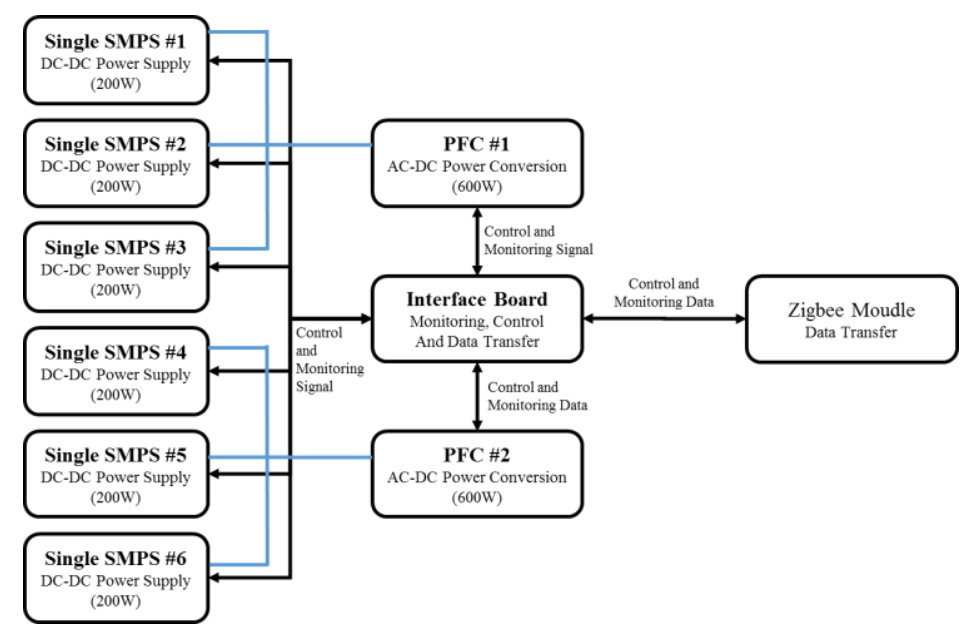

Figure 2. Structure of the Proposed Multiple SMPS Part

Figure 3 illustrates the operational flowchart of the proposed multiple SMPS. As shown in the figure, the PFC is initialized in the initial operation, measuring the output voltage and current. Once the output voltage and current are measured, the multiple SMPS calculates the output power using them and operates PCF \#1 and single SMPS \#1. While PFC \#1 is being operated, it activates single SMPS \#2 when the output power exceeds $200 \mathrm{~W}$ (the maximum power capacity that can be provided by a single SMPS). In sequence, it turns on single SMPS \#3 when the output power exceeds $400 \mathrm{~W}$. When the output power exceeds $600 \mathrm{~W}, \mathrm{PCF} \# 2$ and single SMPS \#4 operate. While the PCF \#2 is being operated, it activates single SMPS \#5 when the output power exceeds $800 \mathrm{~W}$, and single SMPS \#6 is activated when it exceeds $1 \mathrm{~kW}$. This mode of operation minimizes the standby power by supplying the power matching the actual power volume. It also contributes to enhancing the efficiency and power factor of the power supply and maximizing product longevity by reducing the current and voltage stress in power devices.

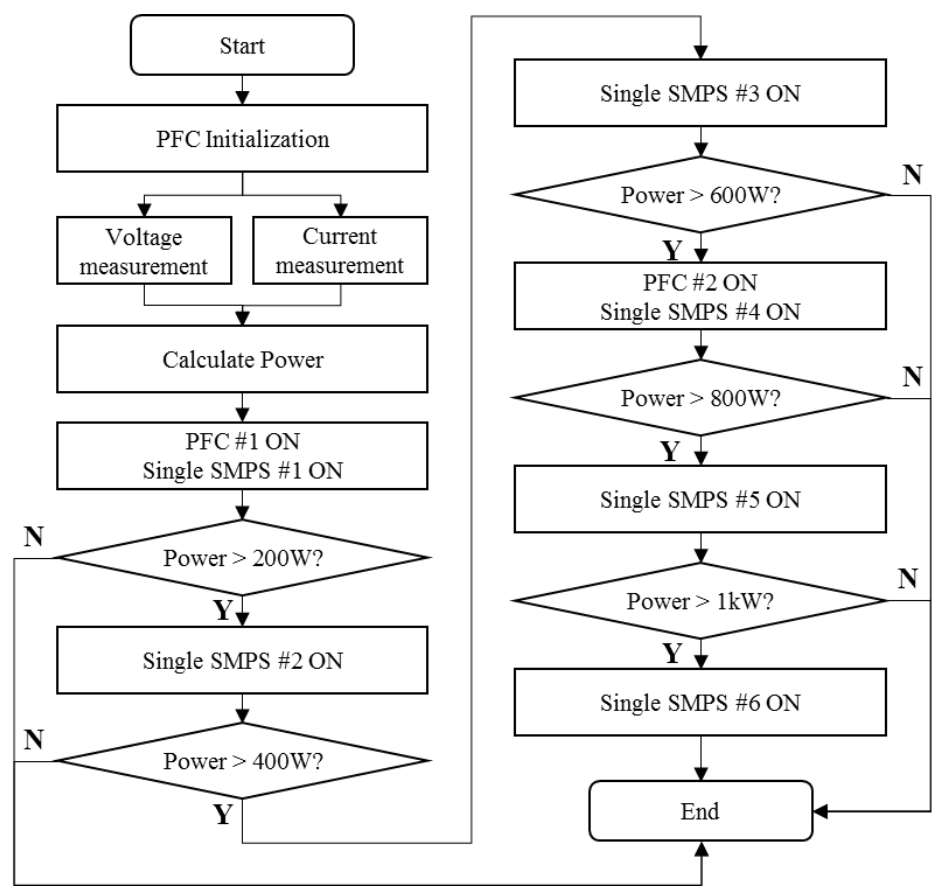

Figure 3. Flow Chart of the Proposed Multiple SMPS Part 


\subsection{Remote Control Part}

The remote control part has a role in controlling and monitoring the power supply part, and comprises a mobile device (an Android-based tablet and a smart phone) and a database server. Connected with each other via a TCP/IP network, the mobile devices for the remote control and the database server transmit monitoring data and receive controlling data for the multiple SMPSs of the power supply part. Linked together via Zigbee, the remote control part and the power supply part exchange both the controlling and monitoring data of the multiple SMPSs [1].

SmpsMonitoring

Multiple SMPS Monitoring Platform

\begin{tabular}{|c|c|c|c|c|c|c|c|c|c|c|c|c|c|}
\hline \multicolumn{3}{|c|}{ Group\#1 } & \multicolumn{4}{|c|}{ Group\#2 } & \multicolumn{3}{|c|}{ Group\#3 } & \multicolumn{3}{|c|}{ Group\#4 } & Single Control \\
\hline Mode & \multicolumn{2}{|c|}{ Manual } & Mode & \multicolumn{3}{|c|}{ Manual } & Mode & \multicolumn{2}{|c|}{ Manual } & Mode & \multicolumn{2}{|c|}{ Manual } & SMPS\#1 \\
\hline Manual & ON & OFF & Manual & ON & & OFF & Manual & ON & OFF & Manual & ON & OFF & SMPS\#2 \\
\hline Auto & ON & OFF & Auto & ON & & OFF & Auto & ON & OFF & Auto & ON & OFF & SMPS\#3 \\
\hline Dimm 100 & $\%$ UP & DN & Dimm & $100 \%$ & UP & DN & Dimm & $100 \%$ UP & DN & Dimm & $100 \%$ UP & DN & SMPS\#4 \\
\hline
\end{tabular}

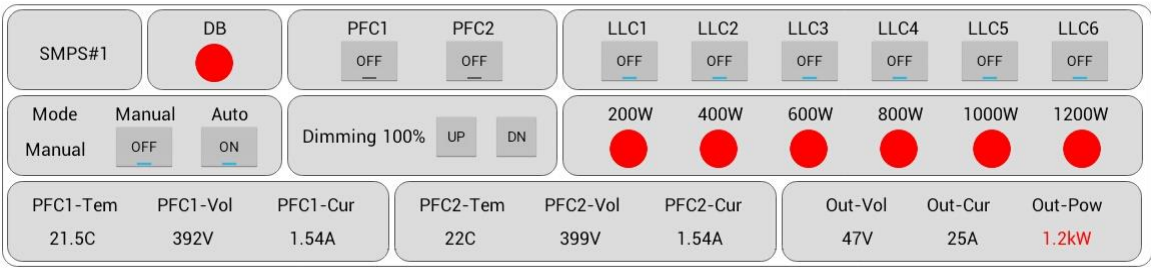

○可

(1) 오후 5:43 과ㅂㅣㅣ

Figure 4. Android-Based Platform for Remote Control and Monitoring GUI

The Android-based platform for remote control and monitoring provides the functions of group control, single control, and monitoring as shown in Figure 4. The group control function performs dimming control simultaneously for a number of multiple SMPSs that are set by groups. The functions of single control and monitoring perform PFC/LLC/dimming control of a multiple SMPS and monitor the PFC voltage/current/temperature and output voltage/current/power.

\section{Experiment and Discussion}

This section deals with the performance evaluation of the proposed system by the performance measurement test for the $1.2 \mathrm{~kW}$ multiple SMPS as a system, and the standardized test of KOLAS, the national certification institution.

\subsection{Experiment 1: Performance Measurement Test Using Actual Power Load (LED)}

The remote control part of the proposed system is combined with a number of multiple SMPSs, but the function test is conducted on only one multiple SMPS for precise measurement. However, the experiment was performed using a set of multiple SMPSs for simplicity: the experiment was conducted in the test environment with an LED as the load; six single SMPSs, two PFCs, and an interface board for SMPS control and communication; a server for communication and data saving, and a tablet (Android platform) for remote control. The test environment was set up as shown in Figure 5. 


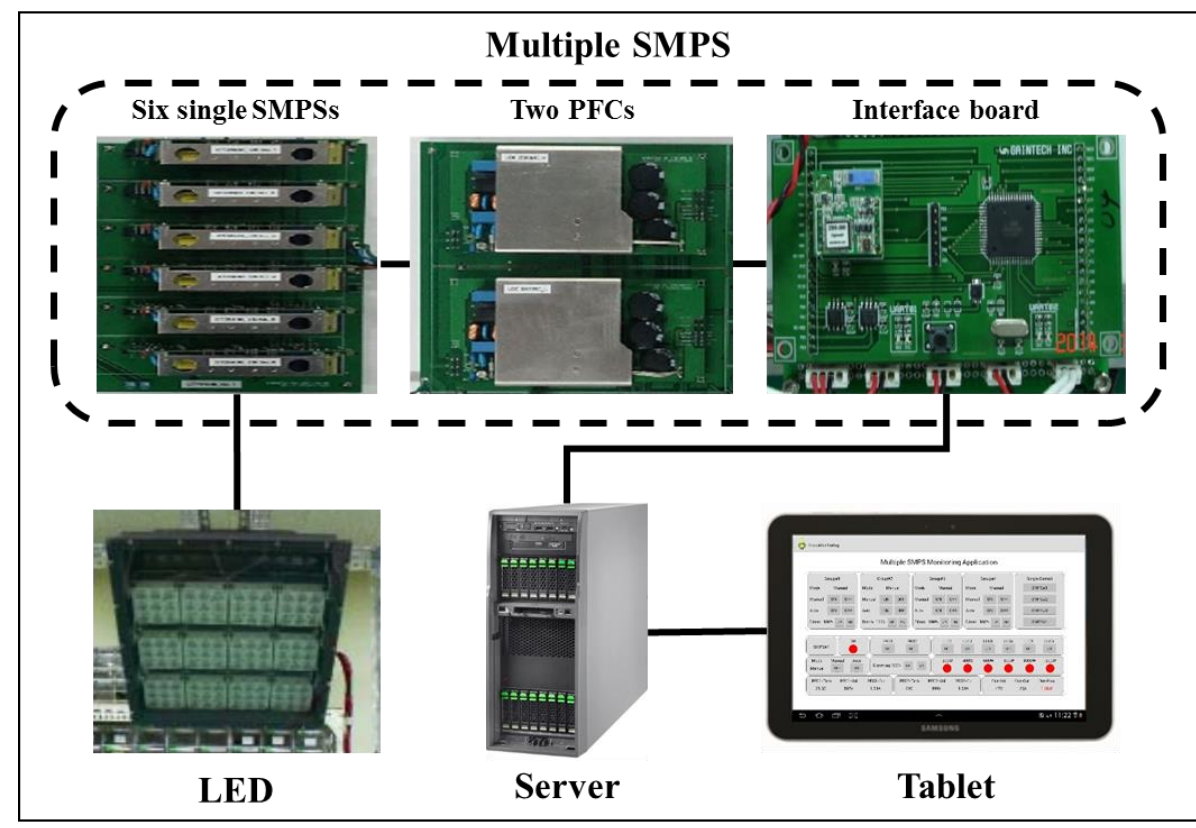

\section{Figure 5. A Test Environment for Performance Measurement using Actual Power Load (LED)}

The performance measurement test result obtained using the $1.2 \mathrm{~kW}$ multiple SMPS applied to an actual power load is shown in Table 1. The efficiency in the measurement test is calculated by dividing the output power by the input power. Comparing the existing system function with the proposed one, we confirmed that the efficiency was increased by only $5 \%$ (the existing system efficiency: $90 \%$. VS, the proposed system efficiency: $95 \%$ ), while the output power was doubled (the existing system power: $600 \mathrm{~W}$, the proposed system power: $1.2 \mathrm{~kW}$ ).

\section{Table 1. Performance Measurement Test Result using Actual Power Load} (LED)

\begin{tabular}{|c|c|c|c|c|}
\hline \multicolumn{5}{|c|}{ Input } \\
\hline $\begin{array}{c}\text { Voltage } \\
\text { (VAC) }\end{array}$ & $\begin{array}{c}\text { Current } \\
(\mathrm{A})\end{array}$ & $\begin{array}{c}\text { Power } \\
(\mathrm{kW})\end{array}$ & $\begin{array}{c}\text { Power } \\
\text { Factor (P.F) }\end{array}$ & $\begin{array}{c}\text { Current } \\
\text { THD }(\% \mathrm{r})\end{array}$ \\
\hline 220 & 5.8 & 1.26 & 0.98 & 6.6 \\
\hline \multicolumn{5}{|c|}{ Output } \\
\hline $\begin{array}{c}\text { Voltage } \\
\text { (VDC) }\end{array}$ & $\begin{array}{c}\text { Current } \\
(\mathrm{A})\end{array}$ & $\begin{array}{c}\text { Power } \\
(\mathrm{kW})\end{array}$ & $\begin{array}{c}\text { Efficiency } \\
(\%)\end{array}$ \\
\hline 48 & 25 & 1.197 & 95 \\
\hline
\end{tabular}

\subsection{Experiment 2: The Standardized Test of KOLAS}

The standardized test was conducted under the supervision of KOLAS, the national certification institution. The experiment was conducted under the conditions of $30 \pm 1^{\circ} \mathrm{C}$ $\mathrm{Ta}$ (ambient temperature) and $22 \pm 1 \% \mathrm{RH}$ (relative humidity). It was aimed at the radiant case, in which a multiple SMPS system was installed as shown in Figure 6. The rated power input $(220 \mathrm{VAC}, 60 \mathrm{~Hz})$ and rated power output load (48 VDC, $1.2 \mathrm{~kW})$ were connected, and each category was measured in the stabilization state (after about $10 \mathrm{~min}$ ). 


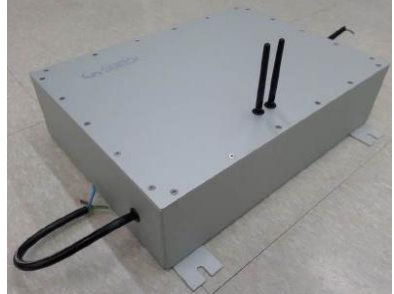

(a) Outside of the Multiple SMPS

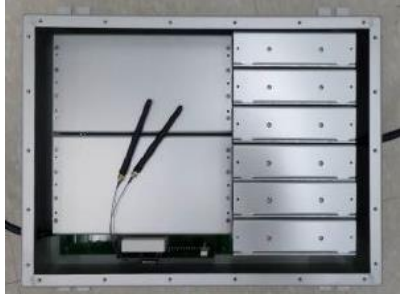

(b) Inside of the Multiple SMPS with Radiant Case

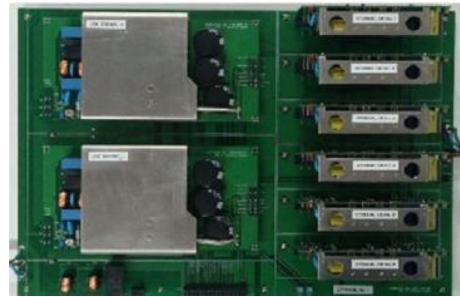

(c) Inside of the Multiple SMPS without Radiant Case

Figure 6. The Standardized Test Environment of KOLAS

The standardized test results are given in Table 2. The test results $(1.204 \mathrm{~kW}$ output power, $95.6 \%$ efficiency) confirmed that the proposed multiple SMPS system can supply high power efficiently.

Table 2. The Standardized Test Result of KOLAS

\begin{tabular}{|c|c|c|c|c|}
\hline \multicolumn{5}{|c|}{ Input } \\
\hline $\begin{array}{l}\text { Voltage } \\
\text { (VAC) }\end{array}$ & $\begin{array}{l}\text { Current } \\
\text { (A) }\end{array}$ & $\begin{array}{c}\text { Power } \\
(\mathrm{kW})\end{array}$ & $\begin{array}{c}\text { Power } \\
\text { Factor (P.F) }\end{array}$ & $\begin{array}{c}\text { Current } \\
\text { THD (\%r) }\end{array}$ \\
\hline 220.2 & 5.8 & 1.26 & 0.99 & 6.6 \\
\hline \multicolumn{4}{|c|}{ Output } & \multirow{2}{*}{$\begin{array}{l}\text { Efficiency } \\
(\%)\end{array}$} \\
\hline $\begin{array}{l}\text { Voltage } \\
\text { (VDC) }\end{array}$ & \multicolumn{2}{|c|}{$\begin{array}{l}\text { Current } \\
\text { (A) }\end{array}$} & $\begin{array}{l}\text { Power } \\
(\mathrm{kW})\end{array}$ & \\
\hline 47.66 & \multicolumn{2}{|c|}{25.26} & 1.204 & 95.6 \\
\hline
\end{tabular}

\section{Conclusion}

In this paper, a multiple SMPS system that is expandable up to $1.2 \mathrm{~kW}$ by operating each $200 \mathrm{~W}$ module of the system as a single unit is presented. The performance of the proposed system is evaluated with a performance measurement test using an actual power load and the standardized test of KOLAS. From the performance measurement test using an actual power load, it was confirmed that the efficiency was increased by only $5 \%$ (the existing system efficiency: $90 \%$, the proposed system efficiency: 95\%), while the output power was doubled (the existing system power: $600 \mathrm{~W}$, the proposed system power: 1.2 $\mathrm{kW})$. The standardized test objectively evaluated the performance of the proposed system and obtained the following test result: $1.204 \mathrm{~kW}$ output power, $95.6 \%$ efficiency. Therefore, it was confirmed that outlet in high power could be efficiently supplied using the proposed multiple SMPS system.

\section{Acknowledgments}

This paper was (partially) supported by the Education and Research Promotion Program of KOREATECH.

\section{References}

[1] Y. S. Kim and J. Ko, "Development of a Sensor Network-based SMPS System - a Smart LED Monitoring Application based on Wireless Sensor Network", International Journal of Distributed Sensor Networks, (2014), pp.1-12.

[2] J. Ko, C.-W. Park and Y. S. Kim, "Development of a Multiple SMPS System Controlling Variable Load Based on Wireless Network", Journal of Electrical Engineering \& Technology, vol.10, no.3, (2015), pp.1221-1226.

[3] Quality, ISCC P., "IEEE recommended practice for monitoring electric power quality", IEEE Std. 1159, (1995). 
[4] B. Giovanni, E. Fiorucci and C. Landi, "Digital measurement station for power quality analysis in distributed environments", IEEE Trans. on, vol. 52, issue 1, (2003), pp. 75-84.

[5] A. Lakashmikanth, M. M. Morcos and W. N. White, "A Real-Time System for Power Quality Testing", IEEE Trans. on, vol. 47, issue 6, (1998), pp. 1464-1468.

[6] M. G. Craford, "LED's challenge the incandescents", IEEE Circuits Device Mag., vol. 8, no. 1, (1992), pp. 24-29.

[7] S. Muthu, F. J. P. Schuurnans and M. D. Pashley, "Red, green, and blue LEDs for white light illunination", IEEE J. Sel. Topics Quantum Electron., vol. 8, no. 2, (2002), pp. 333-338.

[8] B. Jeong and H. Jeong, "LED Lighting Technology Status and Prospects", The Korean Institute of Illuminating and Electrical Installation Engineers, vol. 20, no. 1, (2006), pp. 31-37.

[9] L. Gu, X. Ruan, M. Xu and K. Yao, "Means of eliminating electrolytic Capacitor in AC.DC power supplies for LED lightings", IEEE Trans. Power Electronics, vol. 24, no. 5, (2009), pp. 1399-1408.

[10] D. A. Steigerwald, J. C. Bhat, D. Collins, R. M. Fletcher, M. O. Holcomb, M. J. Ludowese, P. S. Martin and S. L. Rudas, "Illunination with soldi state lignting technology," IEEE J. Sel. Topics Quantum Electron., vol. 8, no. 2, (2002), pp. 310-320.

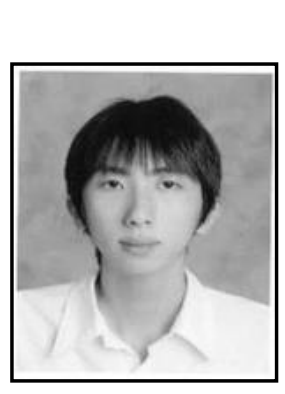

\section{Authors}

Junho Ko, he obtained B.S., M.S., and Ph.D. degrees in School of Computer and Science Engineering, Korea University of Technology Education (KOREATECH), Cheonan, Korea. His research areas include Virtual simulation and Bio-informatics.

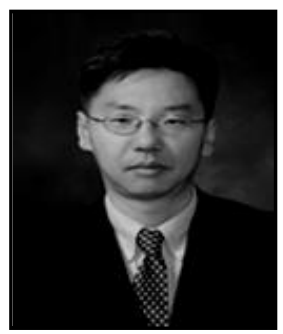

Yoon Sang Kim, he obtained B.S., M.S., and Ph.D. degrees in Electrical Engineering from Sungkyunkwan University, Seoul, Korea, in 1993, 1995, and 1999, respectively. Currently, he is a full professor at the School of Computer and Science Engineering, Korea University of Technology Education (KOREATECH), Cheonan, Korea. His research areas include Virtual simulation, Power-IT technology, and Bio-informatics. 
International Journal of Control and Automation

Vol. 10, No. 11 (2017) 